\title{
Genetic association between two Estrogen Receptor 2 (ER2) Gene Polymorphism (rs4986938 and rs1256049) and SYNTAX Score in Patients with Coronary Artery Disease: A Report from Southern Iran
}

\section{Farzaneh Foroughinia}

Shiraz University of Medical Sciences School of Pharmacy https://orcid.org/0000-0003-3993-2043

\section{Pooyan Dehghani}

Tehran University of Medical Sciences School of Medicine

\section{Mehdi Dianatpour}

Shiraz Medical School: Shiraz University of Medical Sciences

\section{Arghavan Amiri}

Shiraz University of Medical Sciences School of Pharmacy

Iman Jamhiri

Shiraz Medical School: Shiraz University of Medical Sciences

Parisa Ghasemiyeh ( $\nabla$ pa_ghasemeyeh@sums.ac.ir)

Shiraz University of Medical Sciences https://orcid.org/0000-0002-8640-5724

\section{Research article}

Keywords: Cardiovascular disease, Estrogen receptor Beta, Polymorphism, SYNTAX Score

Posted Date: December 15th, 2020

DOl: https://doi.org/10.21203/rs.3.rs-125488/v1

License: (c) (i) This work is licensed under a Creative Commons Attribution 4.0 International License. Read Full License 


\section{Abstract \\ Background}

One of the most common causes of death in the world is coronary artery disease (CAD). Estrogen, the most important early sex hormones in women, plays an important role in the risk reduction of

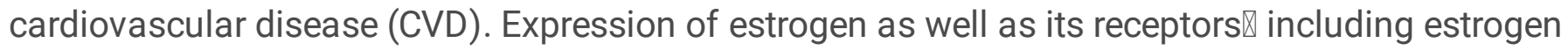
receptor alpha (ER1) and estrogen receptor beta (ER2) might have an association with the severity or complexity of CAD. Since most articles have focused on the relationship between ER1 gene polymorphism and CAD, in this study we aimed to evaluate the association of two ER2 gene polymorphisms, Alul and Rsal, with severity of CAD.

\section{Methods}

148 patients with confirmed CAD who underwent elective percutaneous coronary intervention (PCI) were included in this study. Blood samples were collected before coronary angiography and ER2 gene polymorphisms were analyzed by the PCR-RFLP method. The STNTAX Score (SS), grading system for CAD complexity, was evaluated by an interventional cardiologist who was blinded to other data.

\section{Results}

110 men and 38 women were participated in this study. Our results revealed a statistically significant relationship between SS and Rsal polymorphism of ER2 $(p=0.01)$. In contrast, there was no association between Alul genotypes and SS.

\section{Conclusions}

Besides to estrogen level, the genetic variation of its receptors might play an important role in the severity or complexity of CAD. According to our results, Rsal polymorphism of ER2 gene may assert a pivotal role in the severity of CAD; however this assumption needs to be proved in studies with a larger population.

\section{Background}

Cardiovascular disease (CVD) is considered as one of the major causes of death worldwide. Coronary artery disease (CAD) and cerebrovascular diseases are among the most common causes of deaths due to CVD [1]. According to the epidemiologic studies, premenopausal females have less risk for CVD in comparison with males with the same age that may be because of the protective effects of estrogen in preventing CVD. Estrogen can serve its effect by binding to estrogen receptor a (ER1), estrogen receptor $\beta$ (ER2), and G-protein-coupled estrogen receptor 30 (GPR30). The possible protective mechanism of 
estrogen against CVD would be related to its role on angiogenesis, fibrosis, vascular function, and oxidative stress processes [2].

Estrogen could induce its cardioprotective effects through a receptor-based biological mechanism. Recent researches revealed that genetic variants have an important role in cardio- and cerbro-vascular diseases. For instance, ER1 is an important indicator of atheroprotective effect of estrogen on cardiovascular system. [3]. A study evaluated the association between ER1 single nucleotide polymorphism (SNP) and Intima-media thickness (IMT) in carotid artery, an important predictor of CVD, in female Taiwanese population. This research demonstrated a significant association between ER1(NM_001122740.1):c.1782G >A [rs2228480] and ER1(NM_001122740.1):c.*1753C > A [rs3798758] of female sex with the IMT of carotid artery. According to this article, women with c.1782G $>$ A polymorphism had an increased IMT of carotid artery and were more prone to the risk of atherosclerotic disorders such as ischemic stroke [4]. A case-cohort design on evaluation of the relationship between ER1 gene polymorphism and the risk of coronary heart disease (CHD) and stroke in Finnish population, revealed the significant association of Pvull NM_000125.3:c.453 - 397 T > C [rs2334693 ] polymorphism with the higher risk of $\mathrm{CHD}$ in men. On the other hand, this study failed to confirm any significant association between ER1 gene polymorphism and the occurrence of ischemic stroke [5]. In addition, there was a report for a significant association between ER1 gene polymorphism and low density lipoprotein (LDL) metabolism in women which is an important predictor of atherosclerosis and CVD [6].

Arterial stiffness enhancement and increased wave reflection are the other risk factors for CVD. It has been hypothesized that there is an association between arterial stiffness and genetic variance of ER1, ER2, and CYP19A1 (aromatase). The results of the American population study showed a strong relation between ER1 and ER2 gene polymorphisms and enhanced wave reflection but it is failed to show any association respected to CYP19A1 [7].

The SYNTAX Score (SS) is an angiographic tool using to predict the coronary vasculature characteristics based on the number of lesions and also their complexity, location, and function. SS would be calculated through a computer program using 12 main questions which are about the dominance, number of lesions, segments involved per lesion, total occlusion, trifurcation, bifurcation, aorto-ostial lesion, severe tortuosity, length $>20 \mathrm{~mm}$, heavy calcification, thrombus, and diffuse disease/small vessels. Higher SS would be a predictor of higher level of disease complexity, more challenging pharmacotherapy, and worse prognosis [8].

Since most of studies have focused on ER1 and few studies evaluated the role of ER2 in atherosclerotic diseases, in this study, we aimed to evaluate the association between two major SNPs of ER2 gene containing Alul [rs4986938] and Rsal [rs1256049] and the severity of CAD expressed as SS.

\section{Methods}

The study protocol was assessed and approved by the Ethics Committee of Shiraz University of Medical Sciences (SUMS, Iran) (No: IR.SUMS.REC.1397.369). Written consent form and permission for DNA 
analyses was obtained from all participants.

\subsection{Subjects}

Inclusion criteria were age of $18-80$ years old and confirmed diagnosis of $C A D$ ( $\$ 50 \%$ luminal stenosis in at least one major coronary artery in angiography). Exclusion criteria include consumption of oral contraceptives and hormone replacement therapy during one month prior to the study, malignancy, schizophrenia, connective tissue disease, or chronic inflammatory disease.

Patients who fulfilled the criteria were included into this project. Demographic and clinical data were documented for each patient according to patients' hospital record.

\subsection{Coronary angiography}

Patient who were candidates for invasive strategy with coronary angiography were enrolled into the study. Patients received Aspirin, clopidogrel, statins, and anticoagulation according to current guidelines prior to coronary angiography. Procedure was performed with local anesthesia and via radial or femoral approaches. Ultravist ${ }^{\circledR}$ or Visipaque ${ }^{\circledR}$ was used as contrast agents.

Subjects with $\varangle 50 \%$ stenosis in at least one major epicardial artery greater of $1.5 \mathrm{~mm}$ were included into the study. Coronary angiographic data, including vessels' involvement, percentage of stenosis and SS was evaluated by an interventional cardiologist who was blinded to other data. SS was calculated using the official calculator from SYNTAX score website [9].

The final plan of the management for patients were varied from medical therapy (11\%) to percutaneous coronary intervention (PCl) $(67 \%)$ and coronary artery bypass grafting in the remaining (22\%).

Severe CAD is defined as $\geq 70 \%$ luminal stenosis in one major epicardial vessel or $\geq 50 \%$ stenosis in the left main coronary artery (LMD) and Multivessel disease (MVD) is defined as more than one coronary artery involvement with $\geq 70 \%$ stenosis $[10,11]$.

\subsection{Biological samples and genotyping}

Blood samples were collected in EDTA vacutainer tubes from all patients in order to further assessment of ER2 gene polymorphism. Whole blood was stored at $-20^{\circ} \mathrm{C}$ freezer until use. Genomic DNA for PCR was extracted from whole blood by DNA extraction kit (Yekta tajhiz, Iran) according to manufacturer protocol.

Selected regions of ER2 gene were amplified by polymerase chain reaction (PCR) using specific primers listed in Table 1. All primers used for amplification of Rsal and Alul polymorphisms regions in ER2 gene were designed by the Primer 3 software and were obtained from metabion (metabion international AG, Martinsread, Germany). The reaction program for Rsal and Alul polymorphisms amplification was as follows: initial denaturation for $4 \mathrm{~min}$ at $94^{\circ} \mathrm{C}$, followed by 35 cycles of $94^{\circ} \mathrm{C}$ for $50 \mathrm{~s}, 66^{\circ} \mathrm{C}$ for $50 \mathrm{~s}, 72^{\circ} \mathrm{C}$ 
for $50 \mathrm{~s}$ and final elongation at $72^{\circ} \mathrm{C}$ for $7 \mathrm{~min}$. The PCR reactions were performed in Veriti Thermal Cycler (Applied Biosystems, Foster City, CA, USA).

For RFLP, the PCR products of Rsal and Alul polymorphisms were digested with Rsal (\#ER1121, $5 \mathrm{U}$ at $37^{\circ} \mathrm{C}$ for $16 \mathrm{~h}$ ) and Alul (\#ER0011, $5 \mathrm{U}$ at $37^{\circ} \mathrm{C}$ for $16 \mathrm{~h}$ ) (Fermentas), respectively. DNA fragments from RFLP were electrophoresed on $2 \%$ agarose gel to determine the Rsal and Alul polymorphic patterns.

Table 1. Primers used in this study.

\begin{tabular}{|lll|}
\hline Gene & Sequence & Band size (fragments obtained after digestion) \\
\cline { 1 - 2 } Rsal Forward & TTCTGAGCCGAGGTCGTAGT & $582 \mathrm{bp}$ \\
\cline { 1 - 2 } Rsal Reverse & TGAATCCTTGGACCCAACTC & (A: $293 \mathrm{bp}+289 \mathrm{bp} ; \mathrm{G}: 582 \mathrm{bp})$ \\
\cline { 1 - 3 } Alul Forward & GTGTGTGGTGGGACACAGAG & $646 \mathrm{bp}$ \\
\cline { 1 - 2 } Alul Reverse & AGGCCATTGAGTGTGGAAC & (A: $445 \mathrm{bp}+201 \mathrm{bp} ; \mathrm{G}: 646 \mathrm{bp})$ \\
\hline
\end{tabular}

\subsection{Biostatistical analysis}

Collected information of this study was analyzed using Statistical Package for Social Sciences (SPSS) for Windows software (version 16, Chicago, USA). All continuous variables were reported as the mean \pm $\mathrm{SD}$ and the differences between male and female were analyzed by independent samples $t$ test. Categorical variables were showed as absolute number and percentages and were tested by using the chi-square test.

For comparison between ER2 genotypes and allele frequencies and SS or sex, chi-square test and Fischer's exact test were applied. P-value of $<0.05$ was considered as significant.

\section{Results}

Totally, 148 patients were enrolled into the study. The mean age of all patients was $59.06 \pm 11.42 .110$ (74.7\%) male with the mean age of $57.62 \pm 11.75$ and 38 (25.3\%) female with the mean age of $63.29 \pm$ 9.28 were participated in our study. The same gender distribution was found in previous investigation studied Iranian patients undergoing elective PCI [12].

Clinical baseline characteristics of patients were described in Table 2, dividing participants in two groups according to the sex. Both groups were similar in all variables with exception of age $(p=0.01)$, weight $(p=$ $\varangle 0.001)$, glomerular filtration rate (GFR) ( $p=\varangle 0.001)$ and frequency of hypertension $(p=0.02)$, diabetes mellitus (DM) $(p=0.01)$, and active smoking $(p=\varangle 0.001)$. In addition, no significant difference was found between sex and endpoints such as SS, severe CAD, and the number of diseased vessels. 
Table 2

Patients' demographic and clinical characteristics

\begin{tabular}{|c|c|c|c|c|}
\hline Variables & $\begin{array}{l}\text { Total }(n= \\
148)\end{array}$ & $\begin{array}{l}\text { Male }(n= \\
110)\end{array}$ & $\begin{array}{l}\text { Female }(n= \\
38)\end{array}$ & $\begin{array}{l}\mathrm{p}- \\
\text { value }\end{array}$ \\
\hline Age, years, mean $\pm S D$ & $\begin{array}{l}59.06 \pm \\
11.42\end{array}$ & $\begin{array}{l}57.62 \pm \\
11.75\end{array}$ & $63.29 \pm 9.28$ & 0.01 \\
\hline weight, $\mathrm{kg} / \mathrm{m}^{2}$, mean $\pm \mathrm{SD}$ & $\begin{array}{l}77.19 \pm \\
17.27\end{array}$ & $\begin{array}{l}80.93 \pm \\
15.28\end{array}$ & $66.18 \pm 18.26$ & $\varangle 0.001$ \\
\hline $\mathrm{DM}, \mathrm{N}(\%)$ & $60(40)$ & $3(33.6)$ & $22(57.9)$ & 0.01 \\
\hline Hyperlipidemia, N(\%) & $68(45.3)$ & $46(41.8)$ & $21(55.3)$ & 0.15 \\
\hline Hypertension, N(\%) & $74(49.3)$ & $48(43.6)$ & $25(35.8)$ & 0.02 \\
\hline Current smoker, $\mathrm{N}(\%)$ & $68(45.3)$ & $64(57.1)$ & $4(10.5)$ & $\varangle 0.001$ \\
\hline Previous MI, N(\%) & $6(4)$ & $5(4.5)$ & $1(2.6)$ & NA \\
\hline BB-treated, N(\%) & 109(72.7) & $80(71.4)$ & $29(76.3)$ & 0.66 \\
\hline ACE inhibitor-treated, $\mathrm{N}(\%)$ & $93(62)$ & $68(60.7)$ & $25(65.8)$ & 0.66 \\
\hline $\begin{array}{l}\text { GFR (MDRD), } \mathrm{ml} / \mathrm{min} / 1.73 \mathrm{~m}^{2}, \text { mean } \pm \\
\mathrm{SD}\end{array}$ & $\begin{array}{l}77.16 \pm \\
20.28\end{array}$ & $\begin{array}{l}81.41 \pm \\
18.79\end{array}$ & $64.61 \pm 19.53$ & $\varangle 0.001$ \\
\hline Creatinine, $\mathrm{mg} / \mathrm{dL}$, mean $\pm \mathrm{SD}$ & $1.04 \pm 0.22$ & $1.06 \pm 0.21$ & $1.00 \pm 0.25$ & 0.12 \\
\hline $\mathrm{BUN}, \mathrm{mg} / \mathrm{dL}$, mean $\pm \mathrm{SD}$ & $16.31 \pm 6.38$ & $15.86 \pm 5.22$ & $17.64 \pm 8.9$ & 0.15 \\
\hline SYNTAX Score, mean \pm SD & $\begin{array}{l}18.61 \pm \\
11.85\end{array}$ & $\begin{array}{l}17.86 \pm \\
10.85\end{array}$ & $19.79 \pm 13.76$ & 0.38 \\
\hline SYNTAX Score, N(\%) & $41(27.3)$ & $28(25)$ & 13(34.2) & 0.20 \\
\hline$\geq 23$ & 109(72.7) & $84(75)$ & $25(65.8)$ & \\
\hline \multicolumn{5}{|l|}{$\llbracket 23$} \\
\hline Severe CAD, $N(\%)$ & $122(82.4)$ & $90(81.1)$ & $32(84.2)$ & 0.74 \\
\hline Diseased vessel, N(\%) & $51(34.5)$ & $36(33)$ & $15(39.5)$ & 0.66 \\
\hline One vessel & $56(37.8)$ & $44(40.4)$ & 12(31.6) & \\
\hline Two vessel & $40(27)$ & $29(26.6)$ & $11(28.9)$ & \\
\hline \multicolumn{5}{|l|}{ Three vessel } \\
\hline MVD, N(\%) & $74(50)$ & $56(50.9)$ & $18(47.4)$ & 0.71 \\
\hline $\begin{array}{l}\text { Notes: DM Diabetes mellitus; MI Myoc } \\
\text { enzyme inhibitor; GFR Glomerular filtra } \\
\text { disease; MVD Multi-vessel disease }\end{array}$ & $\begin{array}{l}\text { infarction; B } \\
\text { ate; BUN Bloc }\end{array}$ & $\begin{array}{l}\text { 3eta blocker; } \\
\text { urea nitroge }\end{array}$ & $\begin{array}{l}\text { Angiotensin } \\
\text { AD Coronary a }\end{array}$ & rerting \\
\hline
\end{tabular}


All samples were examined for ER2 gene polymorphisms (Rsal and Alul polymorphisms). The gel electrophoresis results after enzymatic digestion are shown in Fig. 1.

Of 148 samples analyzed for Rsal polymorphisms, a statistically significant relationship was found between SS and Rsal genotypes of ER2 gene $(P=0.01)$ but not with Rsal alleles $(P=0.05)$. Of note, AG genotype was found to be the more prevalent ones in patients with $S S \geq 23$. In contrast, there was no association between Alul genotypes and alleles and SS (Table 3). The same results were reported for the association between sex and Rsal and Alul polymorphisms of ER2 gene.

Table 3

Association of sex and SYNTAX score with ER2 gene polymorphisms in patients with CAD.

\begin{tabular}{|c|c|c|c|c|c|c|c|}
\hline \multirow[t]{2}{*}{ Receptor gene } & & \multicolumn{2}{|l|}{ SYNTAX score } & \multirow[t]{2}{*}{ P-value } & \multicolumn{2}{|l|}{ Gender } & \multirow[t]{2}{*}{ P-value } \\
\hline & & $\triangle 23(\mathrm{~N}=109)$ & $\geq 23(N=41)$ & & Male & Female & \\
\hline \multirow[t]{3}{*}{ Alul, N (\%) } & GG & $58(53.2)$ & $25(61)$ & \multirow[t]{3}{*}{0.16} & $61(54.5)$ & $22(57.9)$ & \multirow[t]{3}{*}{0.9} \\
\hline & $A G$ & $37(33.9)$ & $15(36.6)$ & & $40(35.7)$ & 12(31.6) & \\
\hline & AA & $14(12.8)$ & $1(2.4)$ & & $11(9.8)$ & $4(10.5)$ & \\
\hline \multirow[t]{2}{*}{ Alleles, N (\%) } & A & $63(28.9)$ & 19(23.2) & \multirow[t]{2}{*}{0.32} & $64(28.6)$ & 18(23.7) & \multirow[t]{2}{*}{0.41} \\
\hline & G & 155(71.1) & $63(76.8)$ & & $160(71.4)$ & $58(76.3)$ & \\
\hline \multirow[t]{3}{*}{ Rsal, N (\%) } & GG & 101(92.7) & $32(78)$ & \multirow[t]{3}{*}{0.01} & 98(87.5) & $35(92.1)$ & \multirow[t]{3}{*}{0.82} \\
\hline & $A G$ & $7(6.4)$ & $9(22)$ & & 13(11.6) & $3(7.9)$ & \\
\hline & AA & $1(0.9)$ & $0(0)$ & & $1(0.9)$ & $0(0)$ & \\
\hline \multirow[t]{2}{*}{ Alleles, N (\%) } & A & $9(4.1)$ & $9(11)$ & \multirow[t]{2}{*}{0.05} & $15(6.7)$ & $3(3.9)$ & \multirow[t]{2}{*}{0.53} \\
\hline & G & $209(95.9)$ & 73(89) & & 209(93.3) & 73(96.1) & \\
\hline
\end{tabular}

\section{Discussion}

In this study the association between ER2 gene polymorphisms, Rsal and Alul, and SS was evaluated in 148 Iranian patients with CAD. According to our results, CVD risk factors such as hypertension and active smoking were more prevalent in males compared to females. Higher frequency for history of smoking in males is completely predictable since smoking is not a common habit among Iranian women due to cultural issues. Unfortunately, it is in a growing manner in recent years. In contrast, older age, more cases with diseases such as diabetic mellitus and chronic kidney disease (CKD) were reported to be more prevalent in studied females than males. Older ages in studied women is congruent with the fact that women experienced CVD at higher ages than men. In addition, more rates of CKD involvement in female gender may be assumed due to higher rate of DM among women than men in this study. Although there was significant differences regarding some cardiovascular risk factors between genders, it dose not interpreted to difference in SS among these two groups. 
Results of polymorphisms analysis revealed that there was neither significant association between Alul gene polymorphism nor their alleles with SS, on the other hand; a significant association between Rsal genotypes and SS was found. Even though several researches evaluated the association between ER gene polymorphism and CVD prognosis, most of them worked on ER1 gene polymorphisms [13-16] and only few evidences investigated the association between ER2 gene polymorphisms and CVD progress [17].

A recently published case-control study performed on Chinese Han women population evaluated the association of SNPs of ER2 genes, Rsal and Alul, with CAD. Results of this study revealed that there was no significant association between the genotypes and/or haplotypes of these two SNPs and risk of CAD. Further subdivided age-based analysis in this study revealed significantly lower risk of CAD in AG genotypes of Alul in comparison to homozygotes GG carriers in patients younger than 40 years of age. In contrast, homozygotes AA carriers had higher risk of CAD. They concluded that A allele of Alul SNP would be an important predictor of CAD risk in Chinese women younger than 40 years of age. These correlations were not found in Rsal SNP [18]. Another case-control study on Brazilian population with premature CAD revealed a statistically significant association between Alul SNP and CAD and it was introduced as one of the most important independent risk factors for CAD as well as dyslipidemia, elevated levels of triglycerides and apolipoprotein $B$ and low levels of HDL in this research. The homozygote AA genotype was more prevalent in case group in comparison to control group [19]. Results of these studies are not similar to ours since no significant association was found between Alul genotypes and SS in our study. In contrast, AG genotype of Rsal polymorphism was associated to more severe coronary artery stenosis (SS $\geq 23$ ).

There are some other researches worked on other SNPs of ER2 gene, rs1271572. A nested case-control study on Spanish population which was assessed the relationship between three SNPs of ER2 and myocardial infarction (MI) revealed that there was a significant association between rs1271572 SNP and enhanced risk of MI occurrence. This finding was limited to the male sex, therefore; this study suggested the potential role of gender in genetic variance of ER2 gene polymorphisms in MI patients [20]. Another study performed on American population confirmed a significant association between $T$ allele of rs1271572 SNP and higher risk of MI and CVD, however; this association was just seen in female gender. Because of these controversial results on the association of ER2 polymorphisms and risk of CVD occurrence and severity, further studies with larger sample sizes and assessments of patients with different ethnics and genetics would be necessary [17].

The exact mechanism by which ER signaling and ER gene polymorphism play a role on CAD pathogenesis is uncertain. Recent studies revealed that estrogen could induce anti-fibrotic effects in the heart that would be occurred through the ER2 [2]. Results of an in vivo animal study revealed that activation of ER2 could stop the effects of angiotensin II (Ang-II) and endothelin-1 (ET-1) pro-fibrotic signaling thus prevent further cardiac fibrosis. Ang-ll and ET-1 could induce cardiac fibrosis through the inversion of fibroblasts to myofibroblasts and also through the induction of transforming growth factor$\beta 1$ (TGF $\beta 1$ ) which is a known cardiac fibrosis inducer. Estrogen and ER2 agonists could stop TGF $\beta 1$ 
action via cAMP and protein kinase A pathway $[2,21]$. Also previous studies revealed that estrogen administration could enhance ER2 transcript expression and therefore induce its anti-fibrotic effects [22]. It has been reported that ER2 gene overexpression would be a predictive factor of heart function improvement and survival in patients who had a recent history of MI both in males and females [23]. Results of another study on the role of ER1 and ER2 gene expression on the occurrence of neovascularization after ischemic heart disease revealed that both ER1 and ER2 (with the dominance of ER1) might have a pivotal role in estrogen-induced endothelial progenitor cells (EPCs) mobilization and further protection of cardiac function following a recent MI [24]. Another suggestive cardioprotective mechanism of ER2 gene would be through the induction of eNOS expression and further vasodilation in cases of ischemia/reperfusion (I/R) injury, especially in female gender [25]. These researches emphasizes the fact that in addition to the estrogen plasma level and the extent of ER1 and ER2 gene expression, evaluation of ER1 and ER2 genetic variance and polymorphisms would be helpful as predictive measure for identification of high risk patients for CVD and also their prognosis.

Because of the controversies around the role of ER2 SNPs in CVD in different populations, further larger investigations would be necessary in order to confirm our observed association between Rsal polymorphism and SS.

\section{Study Limitations}

The possible limitations of our study were small sample size and unequal number of participants according to their gender (males and females). Also, it is suggested to evaluate the plasma estrogen levels of patients in combination with investigation of ER2 gene polymorphisms in future studies.

\section{Conclusions}

Besides to estrogen level, the genetic variation of its receptors, ER1 and ER2, might play an important role in the pathogensis, severity and complexity of CAD. According to our results, Rsal polymorphism of ER2 gene may assert a pivotal role in the severity of CAD; however this assumption needs to be proved in higher population studies.

\section{Abbreviations}

ER1: Estrogen receptor alpha; ER2:Estrogen receptor beta; SS:SYNTAX score; CVD:Cardiovascular disease; CAD:Coronary artery disease; CHD:Coronary heart disease; MVD:Multi-vessel disease; LMD:Left main coronary artery disease; MI:Myocardial infarction; CKD:Chronic kidney disease; DM:diabetes mellitus; Ang-II:Angiotensin II; ET-1:Endothelin-1; TGF $\beta 1$ :Transforming growth factor- $\beta 1$; EPCs:Endothelial progenitor cells; ACE:Angiotensin converting enzyme; GFR:Glomerular filtration rate; MDRD:Modification of diet in renal disease; GPR30:G-protein-coupled estrogen receptor 30; SNP:Single nucleotide polymorphism; IMT:Intima-media thickness; LDL:Iow density lipoprotein; PCR:Polymerase chain reaction. 


\section{Declarations}

\section{Acknowledgments:}

This paper was extracted from the thesis written by Arghavan Amiri and was financially supported by Pharmaceutical Sciences Research Center, Shiraz University of Medical Sciences, Shiraz, Iran (Grant number: 16775).

\section{Authors' contributions:}

FF participated in study design, acquisition of data, statistical analysis, interpretation of results, manuscript preparation, and critical manuscript revisions. PD contributed to data collection and critical manuscript revisions. MD contributed to data collection and critical manuscript revisions. AA contributed to data collection and manuscript preparation. IJ contributed to data collection and manuscript preparation. PG contributed to data collection, manuscript preparation, and critical manuscript revisions. All authors approved the final version of the manuscript.

\section{Funding:}

This research, extracted from a thesis written by Arghavan Amiri and was financially supported by Pharmaceutical Sciences Research Center, Shiraz University of Medical Sciences, Shiraz, Iran (Grant number: 16775).

\section{Availability of data and materials:}

All data generated or analysed during this study are included in this published article

\section{Ethics approval and consent to participate:}

All procedures performed in this study were in accordance with the ethical standards of the institutional research Committee of Shiraz University of Medical Sciences and with the 1964 Helsinki declaration and its later amendments. All participants signed the written informed consent.

\section{Competing Interests:}

All authors declared that they have no conflict of interest.

\section{References}

1. Townsend N, Wilson L, Bhatnagar P, Wickramasinghe K, Rayner M, Nichols M. Cardiovascular disease in Europe: epidemiological update 2016. European heart journal. 2016;37(42):3232-45.

2. Iorga A, Cunningham CM, Moazeni S, Ruffenach G, Umar S, Eghbali M. The protective role of estrogen and estrogen receptors in cardiovascular disease and the controversial use of estrogen therapy. Biology of sex differences. 2017;8(1):1-16. 
3. Xing D, Nozell S, Chen Y-F, Hage F, Oparil S. Estrogen and mechanisms of vascular protection. Arteriosclerosis, thrombosis, and vascular biology. 2009;29(3):289-95.

4. Wu MM, Hsieh YC, Lien LM, Chen WH, Bai CH, Chiu HC, et al. Association of estrogen receptor \{alpha\} genotypes/ haplotypes with carotid intima-media thickness in Taiwanese women. Angiology. 2010;61(3):275-82.

5. Kunnas T, Silander K, Karvanen J, Valkeapaa M, Salomaa V, Nikkari S. ESR1 genetic variants, haplotypes and the risk of coronary heart disease and ischemic stroke in the Finnish population: a prospective follow-up study. Atherosclerosis. 2010;211(1):200-2.

6. Demissie S, Cupples LA, Shearman AM, Gruenthal KM, Peter I, Schmid CH, et al. Estrogen receptoralpha variants are associated with lipoprotein size distribution and particle levels in women: the Framingham Heart Study. Atherosclerosis. 2006;185(1):210-8.

7. Peter I, Kelley-Hedgepeth A, Huggins GS, Housman DE, Mendelsohn ME, Vita JA, et al. Association between arterial stiffness and variations in oestrogen-related genes. Journal of Human Hypertension. 2009;23(10):636-44.

8. Sianos G, Morel M-A, Kappetein AP, Morice M-C, Colombo A, Dawkins K, et al. The SYNTAX Score: an angiographic tool grading the complexity of coronary artery disease. Eurolntervention. 2005;1(2):21927.

9. [August 2020]. Available from: http://www.syntaxscore.com/.

10. Sharma B, Wyeth R, Kolath G, Gimenez H, Franciosa J. Percutaneous transluminal coronary angioplasty of one vessel for refractory unstable angina pectoris: efficacy in single and multivessel disease. Heart. 1988;59(3):280-6.

11. Kreatsoulas $C$, Natarajan $M$, Khatun R, Velianou J, Anand S. Identifying women with severe angiographic coronary disease. Journal of internal medicine. 2010;268(1):66-74.

12. Foroughinia F, Salamzadeh J, Namazi MH. Protection from Procedural Myocardial Injury by Omega-3 Polyunsaturated Fatty Acids (PUFA s): Is Related with Lower Levels of Creatine Kinase-MB (CK-MB) and Troponin I? Cardiovascular therapeutics. 2013;31(5):268-73.

13. Evangelopoulos D, Alevizaki M, Lekakis J, Cimponeriu A, Papamichael C, Kominakis A, et al. Molecular analysis of the estrogen receptor alpha gene in men with coronary artery disease: association with disease status. Clinica chimica acta. 2003;331(1-2):37-44.

14. Shearman AM, Cupples LA, Demissie S, Peter I, Schmid CH, Karas RH, et al. Association between estrogen receptor a gene variation and cardiovascular disease. Jama. 2003;290(17):2263-70.

15. Casazza K, Page GP, Fernandez JR. The association between the rs2234693 and rs9340799 estrogen receptor a gene polymorphisms and risk factors for cardiovascular disease: a review. Biological Research for Nursing. 2010;12(1):84-97.

16. Alevizaki M, Saltiki K, Cimponeriu A, Kanakakis I, Xita N, Alevizaki C, et al. Severity of cardiovascular disease in postmenopausal women: associations with common estrogen receptor a polymorphic variants. European Journal of Endocrinology. 2007;156(4):489-96. 
17. Rexrode KM, Ridker PM, Hegener HH, Buring JE, Manson JE, Zee RY. Polymorphisms and haplotypes of the estrogen receptor- $\beta$ gene (ESR2) and cardiovascular disease in men and women. Clinical chemistry. 2007;53(10):1749-56.

18. Shen C, Chen Z, Mahmoodurrahman M, Chen X. Single nucleotide polymorphisms of ER $\beta$ and coronary atherosclerotic disease in Chinese Han women. International Journal of Clinical and Experimental Pathology. 2015;8(2):2044.

19. de Padua Mansur A, Nogueira CCM, Strunz CM, Aldrighi JM, Ramires JAF. Genetic polymorphisms of estrogen receptors in patients with premature coronary artery disease. Archives of medical research. 2005;36(5):511-7.

20. Domingues-Montanari S, Subirana I, Tomás M, Marrugat J, Sentí M. Association between ESR2 genetic variants and risk of myocardial infarction. Clinical chemistry. 2008;54(7):1183-9.

21. Pedram A, Razandi M, Narayanan R, Levin ER. Estrogen receptor beta signals to inhibition of cardiac fibrosis. Molecular and cellular endocrinology. 2016;434:57-68.

22. lorga A, Li J, Sharma S, Umar S, Bopassa JC, Nadadur RD, et al. Rescue of pressure overload-induced heart failure by estrogen therapy. Journal of the American Heart Association. 2016;5(1):e002482.

23. Schuster I, Mahmoodzadeh S, Dworatzek E, Jaisser F, Messaoudi S, Morano I, et al. Cardiomyocytespecific overexpression of oestrogen receptor $\beta$ improves survival and cardiac function after myocardial infarction in female and male mice. Clinical Science. 2016;130(5):365-76.

24. Hamada H, Kim MK, Iwakura A, li M, Thorne T, Qin G, et al. Estrogen receptors a and b mediate contribution of bone marrow-derived endothelial progenitor cells to functional recovery after myocardial infarction. Circulation. 2006;114(21):2261-70.

25. Gabel SA, Walker VR, London RE, Steenbergen C, Korach KS, Murphy E. Estrogen receptor beta mediates gender differences in ischemia/reperfusion injury. Journal of molecular and cellular cardiology. 2005;38(2):289-97.

\section{Figures}




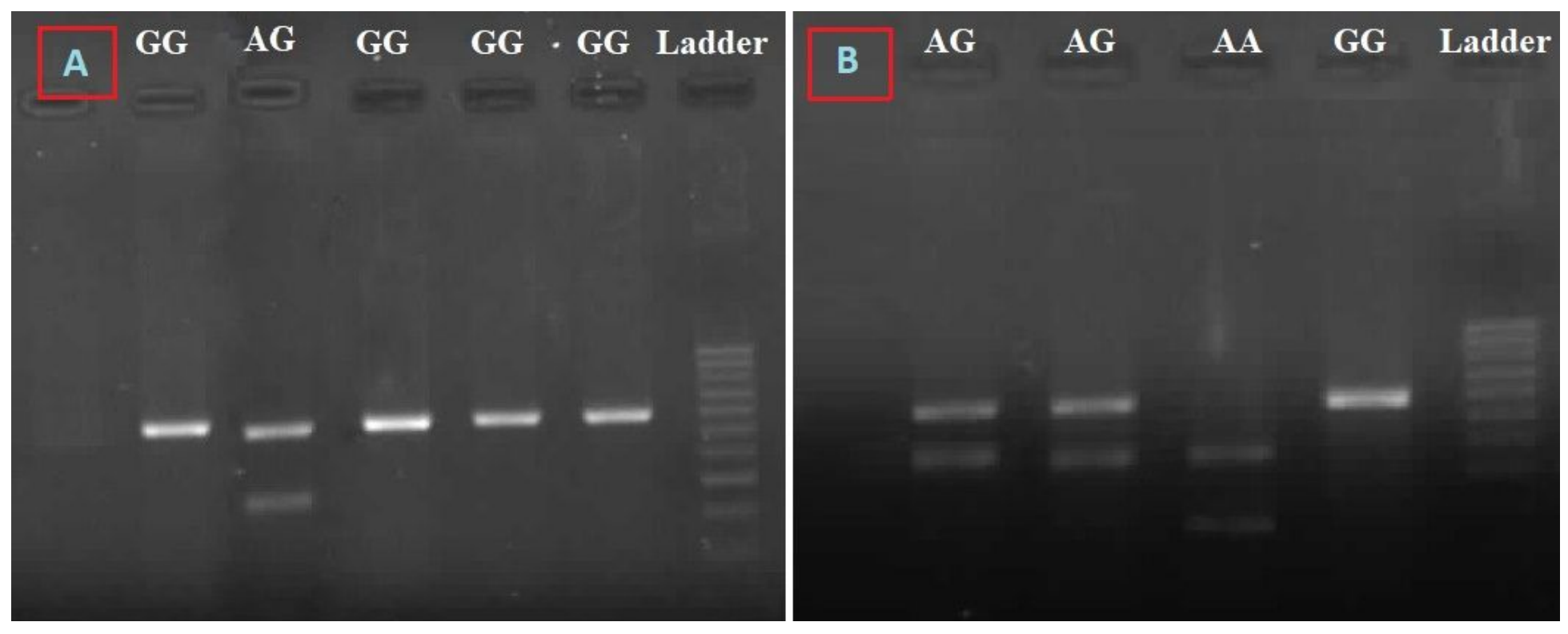

\section{Figure 1}

The gel electrophoresis results after enzymatic digestion. A) Genoypes of Rsal polymorphisms. B) Genoypes of Alul polymorphisms. 100 bp ladder used. 